\title{
Acculturation-Related Factors of Dietary Pattern Changes among Indigenous Adolescents in Mt. Arayat, Philippines
}

\author{
Mark Spencer K. Barcena ${ }^{1 *}$, Anna Teresa O. Orillo ${ }^{1}$, \\ Clarissa B. Juanico ${ }^{1}$, Arvin Paul P. Tuaño ${ }^{1,2}$ \\ ${ }^{1}$ Institute of Human Nutrition and Food, College of Human Ecology, \\ University of the Philippines Los Baños, College, Laguna 4031, Philippines \\ ${ }^{2}$ Institute of Chemistry, College of Arts and Sciences, \\ University of the Philippines Los Baños, College, Laguna 4031, Philippines
}

\begin{abstract}
This study aimed to determine the levels of dietary acculturation and factors affecting acculturationrelated changes in dietary patterns of 15 adolescents in an indigenous community in Mt. Arayat, Central Luzon, Philippines displaced after the eruption of Mt. Pinatubo in 1991. Mixed-methods sequential explanatory design (using modified scales) was employed to measure dietary acculturation; index analyses to evaluate dietary patterns; and focus group discussion to determine factors leading to dietary acculturation. Majority was found to be bicultural $(93.33 \%)$ and the mean dietary pattern index score was 69.40 implying a need for dietary improvement. Moderate to high levels of dietary acculturation were observed on the traditional food block, while low to moderate levels were observed towards the dominant food block. Various psychosocial factors driving dietary choices cumulatively affect dietary patterns of adolescents experiencing acculturation in this study, including but not limited to: 1) the neighboring communities' ethnocultural composition facilitates acculturation primarily through language fluency; 2) prevalence of discrimination exerts an external pressure to adopt host culture for social acceptance; 3) economic need for integration to sustain day-to-day activities exists; 4) religious feasts and gatherings centered on foods previously unknown to them have been introduced; 5) food selection behavior shifts due to acquired experiences of food whether sensory or cognitive; and 6) their attitudes towards assimilation majorly characterizes the gradual internalization of host culture.
\end{abstract}

Keywords: acculturation, adolescents, dietary acculturation, dietary change, dietary pattern

\section{INTRODUCTION}

Changes in behavioral patterns have been happening over the past few decades and these have been brought by constant intercultural contact between cultural groups facilitated by the process of acculturation. According to Satia (2010), acculturation is the process by which a minority group adopts the cultural patterns of the dominant host group and this process is both multidimensional and complex as it also enables the adoption of dietary patterns of the host group more specifically through the aspect of dietary acculturation.

Dietary acculturation occurs in a dynamic manner. It does not only happen linearly, but several studies suggest that dietary acculturation can also happen bi-dimensionally, i.e., immigrants may either retain their traditional ways or consume new foods (Satia 2010). As it is affected by different factors, dietary acculturation results in changes in immigrants' attitudes and beliefs about food, taste preferences, food purchasing, and even food preparation behaviors, thus, leading ultimately to changes in dietary patterns (Satia-Abouta 2003).

Several studies have reported acculturation process in various contexts of immigrant populations: Filipino Americans in North Carolina and New Jersey as studied by Serafica (2011), and Vargas and Jurado (2015) respectively; Southeast Asians in South Korea by Lee et al. (2017); South Asians in Canada by Lesser et al. (2014); and the Hispanic/Latino youths in the United States by Arandia et al. (2018). Some also studied acculturation in the context of indigenous peoples in the world such as that of Holmes and Clark (1992) investigating

\footnotetext{
"Corresponding Author: tel: +639171779927, email: mkbarcena@up.edu.ph
} 
the indigenous peoples of Venezuela's Amazon Territory, the Dogrib Indians of Canada by Ritenbaugh et al. (1995), and the indigenous peoples of Chile by Schnettler et al. (2013).

The Pinatubo indigenous peoples in Luzon, Philippines belong to the oldest population of indigenous peoples of the country, the Negritos, believed to be the first dwellers of the archipelago. An estimated 10,000 members of this indigenous group lived in the areas of Mt. Pinatubo in Central Luzon, in the mountain ranges of Tarlac, Zambales, and Pampanga (and also Bataan). However, the Mt. Pinatubo eruption in 1991 displaced these populations in the nearby lowlands, later finding resettlements (Seitz 1998). This has changed the food environment landscape of the indigenous community, confronted with overlapping food systems that include primarily market-based foods, opposite to their traditional food system. Since the dispense of urban transitions, non-agricultural enterprises and establishments, where industrial services are offered, dominated the food landscape implicating agriculture, food production, and the entirety of food systems (Satterthwaite et al. 2010). Thus, this has brought major changes in diet demands, influencing acculturation trajectories in these indigenous populations. However, dietary acculturation happening in the context of indigenous populations in the Philippines remains unexplored, especially those that are internally displaced from their traditional environments.

Studies focusing on acculturation-related dietary pattern shifts of these indigenous populations will help in further understanding the current and continually evolving food preferences, food systems, food preparation practices and behaviors in these communities that may lead to the development of programs and interventions geared towards addressing their needs. This study aimed to investigate the possible associations between levels of acculturation, dietary acculturation, and dietary patterns of indigenous adolescents in Mt. Arayat, Central Luzon, Philippines.

\section{METHODS}

\section{Design, location, and time}

A cross-sectional study design was used in this study with an explanatory sequential mixedmethods approach to assess the acculturation- related changes in dietary patterns from a group of adolescents aged 13-19 in an indigenous community in Mt. Arayat, Central Luzon, Philippines. The study reported here was conducted from October to November in 2019.

\section{Sampling}

Total population sampling was employed in the study with a total of 18 adolescents recruited. However, three respondents refused and did not give consent for the interview.

\section{Data collection}

Qualitative and quantitative methods of data collection were used. Four questionnaires were answered through personal interviews. A focus group discussion (FGD) was conducted to discuss existing dietary habits (knowledge, attitudes, and values) in relation to dietary intake using an FGD guide.

Research background, objectives, and methods, particularly the research instruments, were presented and discussed with the community leader, chieftain, and the community's council of elders, in their native language before consent was obtained for the study. Participation of the respondents in the study was strictly voluntary. While the community elders provided assistance during the interview sessions with the recruited adolescents, measures to reduce social desirability bias were undertaken such as cross-referencing of data and communicating response confidentiality. Moreover, participants were reassured of complete anonymity throughout the process.

Socioeconomic and demographic data. The following set of information was collected: age, sex, income, geographical characteristic, educational level, marital status, number of children as well as migration-specific data including years of residency in the community.

Acculturation. A modified questionnaire derived from the Acculturation, Habits, and Interests Multicultural Scale for Adolescents (AHIMSA) as reported by Arandia et al. (2018) was used to measure level of acculturation. The modified scale was a 5 -item questionnaire with four response options: 1) Dominant Culture; 2) Traditional Culture; 3) Both; and 4) Neither, measuring four factors including food, language, music, and clothing.

Frequencies of responses were counted for each scale item to compute for subscale scores 
used in classifying respondents into one of the four acculturation categories: Assimilated (i.e., high dominant culture orientation based on "Dominant Culture" responses); Separated (high traditional culture orientation based on "Traditional Culture" responses); Integrated (bicultural orientation based on "Both" responses); and Marginalized (neither of the orientation based on "Neither" responses). The modified questionnaire was pretested and had a calculated Cronbach's alpha coefficient of 0.69 .

Dietary acculturation. The level of dietary acculturation was determined using a modified scale adapted from the Dietary Acculturation Questionnaire for Filipino Americans (DAQFA) as reported by Serafica et al. (2013). The modified scale consisted of two different subscales: the traditional food block and the dominant food block. The scale was a list of 13 food and dietary behavior items reflecting both the traditional and dominant culture food choices and eating patterns, i.e., an 8 -item dominant food block and a 5-item traditional flood block.

Responses were collected through a 5-point Likert-type scale (0-Never; 1-Sometimes; 2-One to three times a month; 3-One to two times a week; 4-Three to four times a week; and 5-Daily). Scores were computed by summing the responses. Any score of more than 28 in the dominant block was considered high, 20-28 moderate, and scores below 20 were considered low. On the traditional block, any score more than 15 was considered high, 10-15 moderate, and scores below 10 were considered low. The calculated Cronbach's alpha of the modified scale was 0.81 for the traditional food block and 0.89 for the dominant food block.

Dietary intake and pattern. Multiple 24-h food recalls were used to record quantitative information of foods and beverages consumed through multiple-pass methods. All foods and beverages consumed were categorized according to the identified dietary components in the indexbased analysis designed to reflect individual dietary pattern determining adherence to the Nutritional Guidelines for Filipinos (NGF).

Dietary intake was based on the average of two 24-h food recalls scored according to the agespecific recommendations outlined in the Daily Nutrition Guide Pyramid (DNGP) for Filipino Teens in the identified dietary components: a) food variety; b) rice and alternatives; c) fish, meat and poultry; d) milk and milk products; e) fruits and vegetables; f) sweets and sugars; g) fats and oils; h) sodium; and i) alcohol.

Total score ranged between 0-100, with a higher score indicating better dietary pattern. Each component was scored out of ten, with 0 indicating unmet recommended amounts, and 10 indicating met dietary recommendations. Scores were proportioned between the maximum and minimum scores based on dietary intake. A total score of more than 80 was considered good, 51-80 needs improvement, and scores less than 51 were considered poor, as adopted from the Healthy Eating Index of the United States Department of Agriculture (USDA-FNS 2018).

\section{Data analysis}

Transcribed interview data were coded and subjected to thematic analysis. On the other hand, quantitative data analyses were conducted using STATA 12 (StataCorp LLC, TX USA). Descriptive statistics was used to summarize socioeconomic and demographic characteristics of the respondents as well as the acculturation, dietary acculturation, and dietary pattern index scores. Point-Biserial Correlation Analysis was employed to variables of nominal and ratio levels (acculturation and dietary acculturation; acculturation and dietary pattern) while Pearson's Correlation Analysis was employed to variables of both ratio level (dietary acculturation and dietary pattern).

\section{RESULTS AND DISCUSSION}

\section{Analysis of quantitative data}

Sample characteristics. The sociodemographic and economic characteristics of the participants are presented in Table 1. The total sample $(N=15)$ consisted of eight male participants and seven female participants. A greater number of respondents were from the younger adolescents ages 13 and 14 (total of 6). All of the respondents were born in the community. Only two of the respondents have graduated from elementary (13.33\%) and only one proceeded to secondary education. Two of the respondents are married $(13.33 \%)$ and one of them already has a child (6.67\%). The monthly income of all the respondents was estimated to be less than 10,000 Philippine pesos (100\%).

Levels of acculturation and dietary acculturation. Acculturation levels are presented 
Table 1. Sociodemographic and economic characteristics of indigenous adolescents in Mt. Arayat, Central Luzon, Philippines

\begin{tabular}{|c|c|c|}
\hline Variable & $\begin{array}{l}\text { Number of } \\
\text { adolescents } \\
\text { (n) }\end{array}$ & $\begin{array}{c}\text { Relative } \\
\text { frequency } \\
\quad(\%)\end{array}$ \\
\hline \multicolumn{3}{|l|}{ Gender } \\
\hline Male & 8 & 53.33 \\
\hline Female & 7 & 46.67 \\
\hline \multicolumn{3}{|l|}{ Geographical characteristics } \\
\hline Nayon/Barangay & 15 & 100.00 \\
\hline \multicolumn{3}{|l|}{ Age (in years) } \\
\hline 13 & 3 & 20.00 \\
\hline 14 & 3 & 20.00 \\
\hline 15 & 2 & 13.33 \\
\hline 16 & 1 & 6.67 \\
\hline 17 & 1 & 6.67 \\
\hline 18 & 1 & 6.67 \\
\hline 19 & 4 & 26.67 \\
\hline \multicolumn{3}{|l|}{ Level of education } \\
\hline Elementary level & 13 & 86.66 \\
\hline Elementary graduate & 1 & 6.67 \\
\hline Highschool level & 1 & 6.67 \\
\hline \multicolumn{3}{|l|}{ Marital status } \\
\hline Single & 13 & 86.67 \\
\hline Married & 2 & 13.33 \\
\hline \multicolumn{3}{|l|}{ Number of child } \\
\hline 0 & 14 & 93.33 \\
\hline 1 & 1 & 6.67 \\
\hline \multicolumn{3}{|l|}{ Family income } \\
\hline$<10,000$ & 15 & 100.00 \\
\hline
\end{tabular}

in Table 2. Almost all of the adolescents were found to be integrated $(93.33 \%)$ except for one assimilated adolescent (6.67\%). No adolescent was found to be either separated or marginalized. Foods eaten at home and the language often used by the respondents both came from the dominant and traditional cultures. Majority of them celebrated a combination of holidays and feasts originating from both cultures. However, most of them listened to songs $(60 \%)$ and wore clothes $(86.67 \%)$ of the dominant culture.
On the other hand, dietary acculturation categorical scores showed that majority of the respondents had high and moderate levels of dietary acculturation (46.67\%) particularly to the traditional food block which reflected traditional food choices and eating patterns of the indigenous group. However, most of them had moderate levels specific to the dominant food block $(66.67 \%)$ which consisted of modern food choices and eating patterns. The mean traditional dietary acculturation score was $15.20 \pm 4.77$ on a scale of $0-25$ and the dominant dietary acculturation score was $20.93 \pm 4.80$ on a scale of $0-40$. Table 3 shows the distribution analysis of each dietary acculturation scale items comprising the different food blocks. Majority of the adolescents often consumed foods from the traditional food block while some items of the dominant food block were rarely-to-never consumed by the indigenous adolescents. Interestingly, dominant items 2 and 3 and traditional item 4 had been consumed on a daily basis by the majority of the indigenous adolescents in this study while dominant items 1 and 6 were never consumed (Table 3).

Dietary pattern scores. Only one of the participants had a dietary pattern found to be of 'good' status $(6.67 \%)$ according to the index analysis conducted while the remaining adolescents were found to be of 'needs improvement' status $(93.33 \%)$. The mean dietary pattern of score was $69.40 \pm 9.23$ on a scale of 0-100 classified as 'needs improvement'.

Correlation between acculturation, dietary acculturation, and dietary pattern. A very weak, positive linear relationship between acculturation and traditional dietary acculturation $\left(r_{\mathrm{pb}}=0.156^{\mathrm{ns}}\right)$ and a weak, positive linear relationship between

Table 2. Acculturation categories of indigenous adolescents in Mt. Arayat, Central Luzon, Philippines

\begin{tabular}{lcc}
\hline Category & $\begin{array}{c}\text { Number of } \\
\text { adolescents } \\
(n)\end{array}$ & $\begin{array}{c}\text { Relative } \\
\text { frequency } \\
(\%)\end{array}$ \\
\hline Assimilated & 1 & 6.67 \\
Integrated & 14 & 93.33 \\
Separated & 0 & 0.00 \\
Marginalized & 0 & 0.00 \\
Total & 15 & 100.00 \\
\hline
\end{tabular}


Dietary pattern changes among Mt. Arayat's indigenous adolescents

Table 3. Dietary acculturation items per block of indigenous adolescents in Mt. Arayat, Central Luzon, Philippines

\begin{tabular}{|c|c|c|c|c|c|c|c|c|c|c|c|c|c|}
\hline \multirow{2}{*}{ Block } & \multirow{2}{*}{ Item } & \multicolumn{2}{|c|}{ Never } & \multicolumn{2}{|c|}{ Rarely } & \multicolumn{2}{|c|}{$1-3 /$ month } & \multicolumn{2}{|c|}{ 1-2/week } & \multicolumn{2}{|c|}{ 3-4/week } & \multicolumn{2}{|c|}{ Daily } \\
\hline & & $n$ & $\%$ & $n$ & $\%$ & $n$ & $\%$ & $n$ & $\%$ & $n$ & $\%$ & $n$ & $\%$ \\
\hline \multirow{5}{*}{ Traditional } & $\begin{array}{l}\text { 1) Locally grown rice \& rice } \\
\text { alternatives }\end{array}$ & 3 & 20.00 & 3 & 20.00 & 2 & 13.33 & 6 & 40.00 & 2 & 13.33 & 2 & 13.33 \\
\hline & 2) Ethnic foods \& dishes & 0 & 0.00 & 4 & 26.67 & 3 & 20.00 & 5 & 33.33 & 1 & 6.67 & 2 & 13.33 \\
\hline & 3) Hunted meat sources & 2 & 13.33 & 2 & 13.33 & 2 & 13.33 & 5 & 33.33 & 2 & 13.33 & 0 & 0.00 \\
\hline & 4) Locally grown vegetables & 0 & 0.00 & 0 & 0.00 & 1 & 6.67 & 4 & 26.67 & 0 & 0.00 & 10 & 66.67 \\
\hline & 5) Locally grown fruits & 0 & 0.00 & 1 & 6.67 & 2 & 13.33 & 5 & 33.33 & 2 & 13.33 & 5 & 3.33 \\
\hline \multirow{8}{*}{ Dominant } & 1) Sweets, cakes or pies & 4 & 26.67 & 10 & 66.67 & 0 & 0.00 & 1 & 6.67 & 0 & 0.00 & 0 & 0.00 \\
\hline & $\begin{array}{l}\text { 2) Milk products, shakes or } \\
\text { ice cream }\end{array}$ & 0 & 0.00 & 6 & 40.00 & 1 & 6.67 & 0 & 0.00 & 2 & 13.33 & 6 & 40.00 \\
\hline & $\begin{array}{l}\text { 3) Packaged or pre-prepared } \\
\text { foods }\end{array}$ & 0 & 0.00 & 2 & 13.33 & 1 & 6.67 & 3 & 20.00 & 3 & 20.00 & 6 & 40.00 \\
\hline & 4) Canned goods & 1 & 6.67 & 3 & 26.67 & 1 & 6.67 & 6 & 40.00 & 2 & 13.33 & 1 & 6.67 \\
\hline & $\begin{array}{l}\text { 5) Sugar-sweetened or } \\
\text { carbonated drinks }\end{array}$ & 0 & 0.00 & 5 & 33.33 & 3 & 20.00 & 4 & 26.67 & 3 & 20.00 & 0 & 0.00 \\
\hline & 6) Fastfood restraurants & 3 & 20.00 & 10 & 66.67 & 1 & 6.67 & 1 & 6.67 & 0 & 0.00 & 0 & 0.00 \\
\hline & $\begin{array}{l}\text { 7) Fries, hotdogs or other } \\
\text { western snacks }\end{array}$ & 0 & 0.00 & 1 & 6.67 & 4 & 26.67 & 7 & 46.67 & 2 & 13.33 & 1 & 6.67 \\
\hline & $\begin{array}{l}\text { 8) Packed ingredients from } \\
\text { supermarkets }\end{array}$ & 1 & 6.67 & 0 & 0.00 & 0 & 0.00 & 0 & 0.00 & 0 & 0.00 & 14 & 93.33 \\
\hline
\end{tabular}

acculturation and dominant dietary acculturation $\left(r_{\mathrm{pb}}=0.3418^{\mathrm{ns}}\right) \quad$ were observed. Although statistically insignificant, these probable relationships signify that as the adolescents move towards an integrative acculturation path, the shift in cultural pattern towards biculturalism affects positively the processes of both the blocks of dietary acculturation characterized by traditional and dominant food items and practices. Also, a weak, statistically insignificant, positive linear relationship was found between acculturation and dietary patterns $\left(r_{\mathrm{pb}}=0.3112^{\mathrm{ns}}\right)$ signifying that integration or biculturalism tended to impact the diet of the indigenous adolescents through inclusion of more food items, thereby increasing diet diversity.

The adolescents' dietary patterns were positively correlated with the traditional block of dietary acculturation $\left(r=0.3484^{\mathrm{ns}}\right)$. However, a negative correlation was observed between dietary pattern and the dominant block of dietary acculturation $\left(r=0.3659^{\text {ns }}\right)$. While these correlations were not found to be of statistical significance, these relationships can possibly explain the finding that although more food items were included in their diet, the components of the traditional food block remained to be its main constituent.

Correlational analysis of the various parameters in this study showed no statistically significant correlations but tended to have associations as supported by the data gathered. This may be due to other psychosocial and economic factors that were in play engendering contextual effects and moderating associations between parameters, thereby affecting dietary patterns. As discussed by Fox et al. (2017), sociocultural circumstances in which acculturation happens may alter health outcomes while other factors may also moderate the relationships constituted in the causal pathway between acculturation and health. Thus, studying such psychosocial and economic factors warrants further investigation in terms of the extent by which internalization of dominant culture, loss of traditional culture, and cultural orientations affect health outcomes. 
Analysis of qualitative data

Given that no statistically significant correlations were established among acculturation, dietary acculturation, and dietary patterns of the indigenous adolescents in this study, the quantitative associations identified have been further studied through an in-person focus group discussion. The factors influencing the lack of significant statistical correlations were explained by the qualitative findings.

Qualities of the pre-disaster indigenous dietary pattern. The indigenous community currently residing in Mt. Arayat in Central Luzon, Philippines, firstly inhabited the mountain slopes of Mt. Pinatubo, which offered excellent opportunities for hunting and gathering. Traditionally, the dietary pattern of this indigenous community was embedded within an egalitarian, communal eating system with tribe members working together from food procurement up to the preparation of meals. The primary foods consumed were naturally outsourced. These included locally grown fruits, vegetables, and tubers while most of their meat sources came from wild pigs, fishes, frogs, snakes, and even fruit and mountain bats.

No advanced cooking methods and techniques were used in the improvement of sensory characteristics and qualities of foods prepared by this indigenous community. No condiments and spices were added. Even salt was rarely used since the procurement of such could only be made through barters or purchases from the lowland communities. The natural abundance of foods for survival had allowed the indigenous communities of Mt. Pinatubo to thrive on their own, however, limiting the diversity of their diets.

\section{Non-directed dietary change among the indigenous community members}

After the Mt. Pinatubo eruption in June 1991, many of the indigenous communities in Mt. Pinatubo had been internally displaced into different evacuation centers in Pampanga, Central Luzon, Philippines. Relief efforts initiated by different government and non-government organizations supplied all the basic necessities needed for their survival. Relief packs distributed were composed of canned goods, instant noodles, rice grains, and other emergency products. These relief packs had permanently shifted not only the dietary patterns of the indigenous communities from Mt. Pinatubo, but also their traditional ways of life.

As a result, new patterns of culture emerged due to the indigenous communities' intercultural contact with the lowlanders. Kuhlein and Receveur (1996) categorized such changes in cultural patterns to be non-directed - a consequence of environmental events such as shifts in climate, natural disasters, weather patterns, military conflict or other political or social upheavals. Thus, the indigenous communities of Mt. Pinatubo had undergone such non-directed change in dietary patterns by which alterations in the availability of foods and the delocalization of food supplies completed the presentation of a new culturally complex set of highly industrial and modernized influences on food and diet.

\section{Acculturation-related forces affecting non- directed changes in dietary patterns \\ Neighboring communities' ethnocultural} composition. According to Sökefeld (1999) as cited in Fox et al. (2017), individuals must be contemplated as elements of communities and cultures forming culturally unique reciprocal relationships due to individual and community interactions. Due to non-isolation of this ethnic enclave, as a result of geographic displacement, this indigenous community was found to be highly surrounded by their dominant lowlander counterparts at present - the Kapampangans/ Tagalogs. With this, cultures of origin were being displaced in consequence of sustained interactions with the dominant culture. Some characteristics of the neighboring community could explain the possible influence of ethnocultural composition to the changes in dietary patterns, i.e., 1) the ability to speak host-community language hastens the acquisition of dietary behaviors as language is necessary for the access of foods in lowland markets; 2) participation to the culture of the neighboring community disengages members of the indigenous community to participate in their traditional activities on food and culture; and lastly, 3) disparity on wanted and actual neighborhood contexts may further obligate the acquisition of host culture dietary patterns.

Discrimination and social acceptance. Discrimination is often directed towards indigenous peoples from the majority of populations, and sometimes, even from social 
institutions. With perceived discrimination, Lindert et al. (2008) explained that it becomes an important acculturative stressor and predictor of acculturation orientations and outcomes, contributing even psychological distress to victims. This has put pressure on the need to assimilate. Furthermore, food-based discrimination also occurs with regard to the consumption of extinct foods like wild birds, snakes, and bats. This resulted in a systematic shift of cultural standards from traditional to a more Westernized form of subjective quality.

Need for integration. The relocation of this indigenous group into the communities of lowlanders had significantly decreased their access to land resulting in a proportionate decline in planting and harvesting activities causing a reduction in the density and variety of foods for consumption. Consequentially, purchasing and consuming of foods available in the lowland markets remained to be one of the alternatives to meet their food needs. The socioeconomic status of the indigenous community predetermined the ability to purchase and procure foods offered in the market. While indigenous community members continued to purchase foods, food affordability still had reduced the choices of foods they could actually purchase. This was congruent to the results found by Ekaningrum et al. (2017) where they studied the associations between nutrient density, food prices, and nutritional status of elementary school children. In the study, it was found that energy density was negatively correlated to food prices. This was also evident in the case of indigenous adolescents studying in the lowland as it was found that some of the adolescents opted for empty-calorie snacks as these were cheaper. While exposure to foods available in the lowland was high, the ability to acquire them and make as components of their dietary patterns was still low. Moreover, facing this economic gap and inequality, the indigenous community members would then grab job and employment opportunities offered in lowland communities reinforcing host-culture exposure, resulting in the acquisition of lowland food patterns.

Religious influences. The indigenous community of Mt. Arayat had been converted into Christianity since 2002. The change in religious identity into a more Western demarcation not only implicated their former spiritual culture, but also various habitual dietary customs. While dietary rules were less formally regulated in Christianity, it still deeply governed many religious feasts like Lent, Easter, and Christmas. The celebration of these occasions was tantamount to the celebration of foods ascribed to them, actualizing religious faith. Reaffirming this, it was found that religion remained to be a significant influential determinant in peoples' behavior, consumption patterns, and dietary choices (Fuccillo et al. 2016).

Transition in food selection behavior. The process of food selection remains to be dependent on food availability, even overlapping the concepts of food acceptance, rejection, and preferences (Lau et al. 1984). Food selection happens through acquired experiences, sociocultural engagements, and environmental exposures. However, the sensory quality of food can also influence food preferences. Because traditional foods of the indigenous community generally have simple and natural flavors, the participants were likely to prefer purchased foods as these have more rich and distinct flavors.

Attitude towards assimilation. Berry (1997) modeled acculturation as a dynamic process that can happen bi-dimensionally. It can involve both the process of acquisition or avoidance of host culture and the retention or loss of heritage culture. Assimilation, as a cultural orientation, is often characterized by the acquisition of host culture and the concurrent loss of heritage culture. As Berry (2005) indicated, the attitude by which the community responds favorably or unfavorably towards assimilation can modify the extent of host culture exposure and internalization. In the case of the indigenous community in Mt. Arayat, their accepting attitudes towards assimilation led to the gradual internalization of host culture practices and identity. And remarkably, such degree of favorable response specified an acculturation trajectory subsequently changing the community's dietary patterns.

\section{Integration of quantitative and qualitative findings}

Degrees of association between levels of acculturation and dietary acculturation in relation to changing dietary patterns were identified. These relationships were further expounded by the qualitative factors that governed them. While acculturation was found to be positively associated 
with both the food blocks of dietary acculturation, the correlations varied in relatively wide degrees. Explaining the stronger correlation observed between acculturation and dietary acculturation dominant food block $\left(r_{\mathrm{pb}}=0.1561^{\mathrm{ns}}\right)$, the bicultural orientation of the indigenous adolescents $(N=14$; $93.33 \%$ ) advanced into an extent of host culture acquisition introducing further the eating patterns and food choices of the dominant population. Due to better job opportunities in lowland communities, as well as the fluency of host languages, which facilitated the easier access to foods available in lowland markets, these have increased the adolescents' exposure to the host culture thereby impairing retention of traditional food patterns. The transition in food selection behaviors, particularly on food desirability, as well as the presence of religious influences on foods as celebratory components of religious feasts and gatherings, confirmed the positive correlation between acculturation and dietary patterns $\left(r_{\mathrm{pb}}=0.3112^{\mathrm{ns}}\right)$. Thus, there exists linearity in the relationships related to acculturation instigating the process of dietary acculturation, thereby effecting the change in dietary patterns.

However, since it was noted that a positive relationship between the components of the traditional food block of dietary acculturation and dietary patterns $\left(r=0.3484^{\mathrm{ns}}\right)$ existed among adolescents from this indigenous community, this indicated that while there were changes in food and eating behaviors of the adolescents potentially oriented towards the food culture of the dominant society, foods readily available from their natural environment similar to their traditional food practices still mainly constituted their dietary intake, although in relatively decreased amount and utility. Moreover, the negative relationship between the dominant food block of dietary acculturation and dietary patterns $\left(r=-0.3659^{\text {ns }}\right)$ strengthened the observation that food purchasing power greatly limited their alternative access to obtain and consume foods from lowland markets such as milk, meat, and fruits. Hence, while it was found that the processes of acculturation and dietary acculturation continually happen in a gradual manner, these were still hindered chiefly by the socioeconomic status of the indigenous adolescents in this study.

With these aggregated data, dietary change as a consequence of geographical displacement and psychosocial factors in an acculturative process can be viewed from either of the following positions: as a positive change on a much-improved Western mode of food production and consumption particularly as an increase in diet diversity, or as a negative change with Western food production and consumption delocalizing traditional food patterns. Studies on acculturation showed that increased consumption of fats and sugars and less on fruits and vegetables led to a higher body mass index (Serafica 2011; Vargas \& Jurado 2015) and higher risks of illhealth and chronic diseases due to the major gap in indigenous peoples' relationship to food led to indigenous food insecurity and health changes (Skinner et al. 2016).

However, it was also purported that the modernization of diet has neither caused a deterioration nor a notable improvement in dietary patterns (Arandia et al. 2018). In fact, while food variety has essentially increased due to the introduction of foods previously excluded from their diets such as essential fats and oils, sugar and sweets, and milk and other milk products, the quantity of fruits, vegetables, and meat products being consumed, was still at levels that had a reducing impact on the total dietary pattern index scores of the indigenous adolescents. Such levels, however, were attributed to the decreased land use and access, disparate from the traditional food pattern of this indigenous community under study. Nevertheless, the emerging accultured trajectory of biculturalism has driven dietary benefits integrating both traditional and modern food patterns.

\section{CONCLUSION}

The examination of the process of acculturation of the indigenous adolescents in Mt. Arayat, Central Luzon, Philippines included in this study indicated how dietary pattern changes were contingent on various contextual factors. While no statistically significant correlations were found between the levels of acculturation, dietary acculturation, and dietary patterns in the study, the probable relationships found provided an understanding on how acculturation prompts the events of dietary acculturation thereby changing dietary patterns, and how psychosocial and economic forces both contribute to these processes being investigated. Moreover, these factors could be the bases of various personal 
and community decisions to consume new foods and become culturally significant components of individual dietary patterns of acculturated and internally displaced populations. This study led to an important viewpoint of integrating contexts in which dietary changes occur, i.e., the development of nutrition and other health programs must tailor-fit the setting of target populations, including acculturated indigenous communities. Biculturalism in indigenous communities, as opposed to the unidimensional perspective, and the health effects of acculturation warrant further investigation

In addition, further comparative and longitudinal studies may also be conducted among various indigenous communities in the Philippines in order to determine effects of acculturation-related dietary changes on indicators of health status, as well as to test the moderating and mediating effects. Methodological work is also essential to the design of various unbiased and culture-specific instruments and methods to accurately gather and measure data such as acculturation and dietary acculturation scales, and index analysis for Filipino dietary patterns.

\section{ACKNOWLEDGEMENT}

We are grateful to the indigenous adolescents who participated in this study and to the leaders of their communities who gave permission and consent for this investigation. We acknowledge the technical assistance of Joana Rose M. Vergara, university researcher at the Agricultural Systems Institute, College of Agriculture and Food Science of the University of the Philippines Los Baños and of Eulalie D. Dulnuan, faculty member and Director of the Ifugao Rice Terraces - Globally Important Agricultural Heritage System Research and Development Center of the Ifugao State University.

\section{AUTHOR DISCLOSURES}

The authors have no conflict of interest.

\section{REFERENCES}

Arandia G, Sotres-Alvarez D, Siega-Riz AM, Arredondo EM, Carnethon MR, Delamater
AM, Gallo LC, Isasi CR, Marchante AN, Pritchard D et al. 2018. Associations between acculturation, ethnic identity, and diet quality among U.S. Hispanic/Latino youth: Findings from the $\mathrm{HCHS} / \mathrm{SOL}$ youth study. Appetite 129:25-36. https:// doi.org/10.1016/j.appet.2018.06.017.

Berry JW. 1997. Immigration, acculturation, and adaptation. Appl Psychol 46(1):5-34. https://doi.org/10.1111/j.1464-0597.1997. tb01087.x.

Berry JW. 2005. Acculturation: Living successfully in two cultures. Int $\mathbf{J}$ Intercult Relat 29(6):697-712. https://doi. org/10.1016/j.ijintrel.2005.07.013.

Ekaningrum AY, Sukandar D, Martianto D. 2017. Association between nutrient density, food price, and nutritional status among Pekayon 16 Pagi elementary school children. J Gizi Pangan 12(2):139-146. http://dx.doi. org/10.25182/jgp.2017.12.2.139-146.

Fox M, Thayer ZM, Wadhwa PD. 2017. Acculturation and health: The moderating role of socio-cultural context. Am Anthropol 119(3):405-421. https://doi. org/10.1111/aman.12867.

Fuccillo A, Sorvillo F, Decimo L. 2016. Law, religions and food choices. CalumetIntercult L Humanit Rev (2):1-25.

Holmes R, Clark K. 1992. Diet, acculturation and nutritional status of Venezuela's Amazon territory. Ecol Food Nutr 27(3-4):163187. https://doi.org/10.1080/03670244.19 92.9991242.

Kuhlein HV, Receuver O. 1996. Dietary change and traditional food systems of indigenous peoples. Annu Rev Nutr 16:417442. https://doi.org/10.1146/annurev. nu.16.070196.002221.

Lau D, Krondl M, Coleman P. 1984. Psychological Factors Affecting Food Selection. New York (US): Plenum Press.

Lesser I, Gasevic D, Lear SA. 2014. The association between acculturation and dietary patterns of South Asian immigrants. PLOS One 9(2):e88495. https://doi. org/10.1371/journal.pone.0088495.

Lee EJ, Lee KR, Lee SJ. 2017. Study on the change and acculturation of dietary pattern of Southeast Asian workers living in South Korea. Appetite 117:2013-213. doi: 10.1016/j.appet.2017.06.022. 
Lindert AT, Korzilius H, Van de Vijer FJR, Kroon S, Arends-Tóth J. 2008. Perceived discrimination and acculturation among Iranian refugees in the Netherlands. Int $\mathbf{J}$ Intercult Relat 32(6):578-588. https://doi. org/10.1016/j.ijintrel.2008.09.003.

Ritenbaugh C, Szathmary E, Goodby S, Feldman C. 1995. Dietary acculturation among the Dogrib Indians of the Canadian Northwest territories. Ecol Food Nutr 35(2):81-94. https://doi.org/10.1080/03670244.1996.99 91478.

Satia JA. 2010. Dietary acculturation and nutrition transition: An overview. Appl Physiol Nutr Metab 35(2):219-223. http:// dx.doi.og/10.1138/H10-007.

Satia-Abouta J. 2003. Dietary acculturation: Definition, process, assessment, and implication. Int J Hum Ecol 4(1):71-86.

Satterthwaite D, McGranahan G, Tacoli C. 2010. Urbanization and its implications for food and farming. Philos Trans R Soc Lond B Biol Sci 365(1554):2809-2820. http:// dx.doi.org/10.1098/rstb.2010.0136.

Schnettler B, Miranda H, Mora M, Lobos G, Viviani J, Sepúlveda J, Orellana L, Denegri M. 2013. Acculturation and consumption of foodstuffs among the main indigenous people in Chile. Int $\mathrm{J}$ Intercult Relat 37(2):249-259. https://doi.org/10.1016/j. ijintrel.2012.08.003.
Seitz S. 1998. Coping strategies in an ethnic minority group: The Aeta of Mount Pinatubo. Disasters 22(1):76-90. https:// doi.org/10.1111/1467-7717.00076.

Serafica RC. 2011. Dietary consumption of fat, sugar, fruits and vegetables, dietary acculturation and anthropometric indicators among Filipino Americans in North Carolina [Dissertation]. Honolulu: University of Hawaii at Mānoa.

Serafica RC, Lane SH, Ceria-Ulep CD. 2013. Dietary acculturation and predictors of anthropometric indicators among Filipino Americans. Sage Open 3(3):2158244013495543. http://dx.doi. org/10.1177/2158244013495543.

Skinner K, Pratley E, Burnett K. 2016. Eating in the city: A review of the literature on food security and indigenous people living in urban spaces. Societies 6(2):7. http:// dx.doi.org/10.3990/soc6020007.

Sökefeld M. 1999. Debating self, identity, and culture in anthropology. Curr Anthropol 40(4):417-448.

[USDA-FNS] United States Department of Agriculture-Food and Nutrition Service. 2018. How the HEI is scored. https://www. fns.usda.gov/how-hei-scored [Accessed 14th September 2019].

Vargas P, Jurado LF. 2015. Dietary acculturation among Filipino Americans. Intl J Environ Res Public Health 13(1):16. https://doi. org/10.3390/ijerph13010016. 